\title{
Disfunção sexual e seu tratamento em pacientes com Diabetes Mellitus
}

Carlos Magno Leite de Alencar*

\section{RESUMO}

O Resumo Comentado trata do trabalho "Uma Visão Geral da Disfunção Sexual e seu Tratamento em Pacientes com Diabetes Mellitus", publicado no Boletim Médico "TERAPÊUTICA EM DIABETES" $\mathrm{n}^{\circ} 22$ que dá orientações para a compreensão da Disfunção Eretiva em pacientes diabéticos, de autoria de Paulo Rodrigues.

A Disfunção Eretiva ocorre em 1/3 dos diabéticos, de instalação em 10 anos de doença. $\mathrm{O}$ mecanismo etiológico é a esclerotização peniana que ocorre sobretudo quando os níveis de Hemoglobina Glicosilada estão aumentados. Há drogas que aumentam o problema e há outras que o tratam. Entre as drogas usadas no tratamento estão: Sildenafil (Viagra®), Fentolamina (Vasomax $®$ ), Auto-Injeção de Agentes Farmacologicamente Ativos e MUSE (Medicated Uretral System). Outras alternativas são: Dispositivo a Vácuo, Revascularização Peniana e Próteses Penianas.

As medidas de controle metabólico devem ser mantidas, como: dieta, atividade física e anti-diabéticos orais ou insulina.

Médico. Delegado Regional da SBRASH. 
O artigo "Uma Visão Geral da Disfunção Sexual e seu Tratamento em Pacientes com Diabetes Mellitus", publicado no Boletim Médico do Centro B-D de Educação em Diabetes, "TERAPÊUTICA EM DIABETES", nº 22 de fevereiro/março/abril de 1999 dá orientações importantes para a compreensão do problema do tratamento da Disfunção Eretiva. A autoria do trabalho é de Paulo Rodrigues.

Um em cada três homens diabéticos apresentarão dificuldade em obter ereção. A instalação da disfunção dar-se-á dentro de 10 anos após o diagnóstico ou como forma de início do Diabetes Mellitus.

$\mathrm{O}$ autor identifica a disfunção Eretiva como a incapacidade e penetração vaginal, dificuldade de manter a ereção ou necessidade excessiva de estimulação manual-erótica para obtê-la.

$\mathrm{O}$ autor aborda o mecanismo da ereção e seu comprometimento no Diabetes Mellitus, ao destacar que o descontrole metabólico da doença leva irreversivelmente à esclerotização peniana, principalmente após os dez anos de diagnóstico do Diabetes e sobretudo onde os níveis de hemoglobina glicosilada estão permanentemente altos.

As drogas que podem comprometer a qualidade eretiva do tecido cavernoso são: diuréticos, fenotiazinas, anti-histamínicos, anti-depressivos tricíclicos, hormônios femininos, digoxina, efedrina, anti-fúngicos, metoclopramida, haloperidol, anorexígenos, cimetidina, anti-androgênicos, metil-dopa, alfa e beta bloqueadores, além do álcool e cigarro. Sua simples substituição ou suspensão pode melhorar a disfunção eretiva.

As alternativas terapêuticas para o tratamento da D.E. são:

SILDENAFIL (Viagra ${ }^{\circledR}$ ) - facilita a ereção por sua ação sobre a enzima fosfodiesterase - 5, elevando a concentração de GMPc, com marcante ação mio-relaxadora. Sucesso clínico em 80-90\%, embora em casos mais graves de diabetes mal controlado ou de longa data, os resultados podem ser comprometidos pela observada diminuição de óxido nítrico nos casos de esclerose celular severa. Efeitos colaterais: cefaléia (15\%), rubor facial (10\%), epigastralgias (6\%), congestão nasal (4\%), diarréias (2\%) e artralgias (2\%). Restrição à droga para usuários de agentes vasodilatadores do tipo nitritos ou pacientes com limitada função cardíaca.

FENTOLAMINA (Vasomax®) - uso oral com sucesso clínico em 85-90\% dos casos. Ação alfa-bloqueadora, promovendo vasodilatação e mio-relaxamento das trabéculas cavernosas. Efeitos colaterais: congestão nasal (20\%), cefaléia (10\%) e náuseas. 
AUTO-INJEÇÃO DE AGENTES FARMACOLOGICAMENTE ATIVOS - drogas aplicadas diretamente no tecido cavernoso para promoverem dilatação e ereção - índice de penetração vaginal de 94-96\%. Efeitos colaterais: priapismo e fibrose peniana.

MUSE (Medicated Uretral System) - prostaglandina de uso intrauretral, com sucesso de 50-60\%. O uso do supositório intra-uretral exige que a relação seja feita com preservativo, pois a ejaculação de prostaglandina na vagina causa desconforto e prurido vaginal.

$\mathrm{O}$ autor cita ainda a iombina, a apomorfina, a bromocriptina, o trazodone e os androgênios.

As alternativas terapêuticas não farmacológicas são:

DISPOSITIVO À VÁCUO - que provoca a entrada de sangue nos corpos cavernosos por sucção. Baixa aderência.

REVASCULARIZAÇÃO PENIANA - cria vias alternativas de influxo sanguíneo. Sucesso relativo com uso restrito a casos raros, de pacientes jovens e com lesões vasculares traumáticas.

PRÓTESES PENIANAS - são verdadeiras hastes de sustentação dos corpos cavernosos. Satisfação clínica em 90-98\% dos casos. Para casais que pretendam complementar suas relações com ereções mais firmes e sustentadas.

Considerando o aqui exposto é óbvio notar que os recursos terapêuticos para o tratamento da Disfunção Eretiva em pacientes com Diabetes Mellitus estão relacionados também a manutenção de medidas de controle metabólico como dieta, atividade física e quando necessário o uso de anti-diabéticos orais ou insulina.

Outras disfunções sexuais presentes em pacientes diabéticos não citadas no texto são Ejaculação Retrógrada, Desejo Sexual Inibido e Anorgasmia. 